\title{
The Structure of a Noun Phrase in Ezha, Ethio-Semitic
}

\author{
Endalew Assefa * \\ (Addis Ababa University, Ethiopia)
}

\begin{abstract}
This article is meant to provide a descriptive account of a noun phrase in the Ezha language. By so doing, no particular theoretical assumption is adhered to; the data analysis is dictated by a purely descriptive perspective. Data for the study were accessed by consulting native speakers through elicitation augmented by recording of spontaneous speech. A noun phrase in Ezha is found out to be built out of a head noun alone or a head noun together with (a) dependent(s). In situations where a noun phrase is made up of a head noun along with dependents, the dependents can be a noun, an adjective, a numeral, a demonstrative and/or a relative clause. The phrase is always head-final.
\end{abstract}

Keywords: noun phrase, Ezha, head, dependent, modifier, complement

\section{Introduction}

Ezha is one of the different Gurage languages, Ethio-Semitic, spoken typically in and around the town of Agenna, Ethiopia. It is spoken by people of whom the majority is Orthodox Christians, some Muslims, and very few Protestants. Most of the Ezha people are farmers residing in the rural area by cultivating Enset 'false banana', while most of those who live in the urban areas are merchants. The area where Ezha is spoken is surrounded to the north-east by Muher, to the south-west by Chaha and to the east by Gumer as depicted by the following figure.

This particular paper deals with the structure of a noun phrase in Ezha from a purely descriptive point of view. The data for the study were collected through elicitation supplemented by recording of free narratives by consulting native speakers of the language.

\section{Discussion}

A noun phrase in Ezha can be formed out of a head noun alone or along with other lexical and grammatical items serving as dependents to the head noun. This phrasal category is always right-headed, hence, no dependent constituent can occur following the head noun. The head is the only obligatory constituent, while the dependents are optional

\footnotetext{
* Dr. Endalew Assefa: Assistant Professor of Linguistics, Department of Linguistics and Philology, College of Humanities, Addis Ababa University, Ethiopia. E-mail: endexye2006@ gmail.com. 


\section{The Structure of a Noun Phrase in Ezha, Ethio-Semitic}

elements which could be either modifiers or complements to the head if they exist.

The head noun within a noun phrase can select another noun (phrase) as a dependent constituent. The dependent noun (phrase) assumes different roles as shown below.
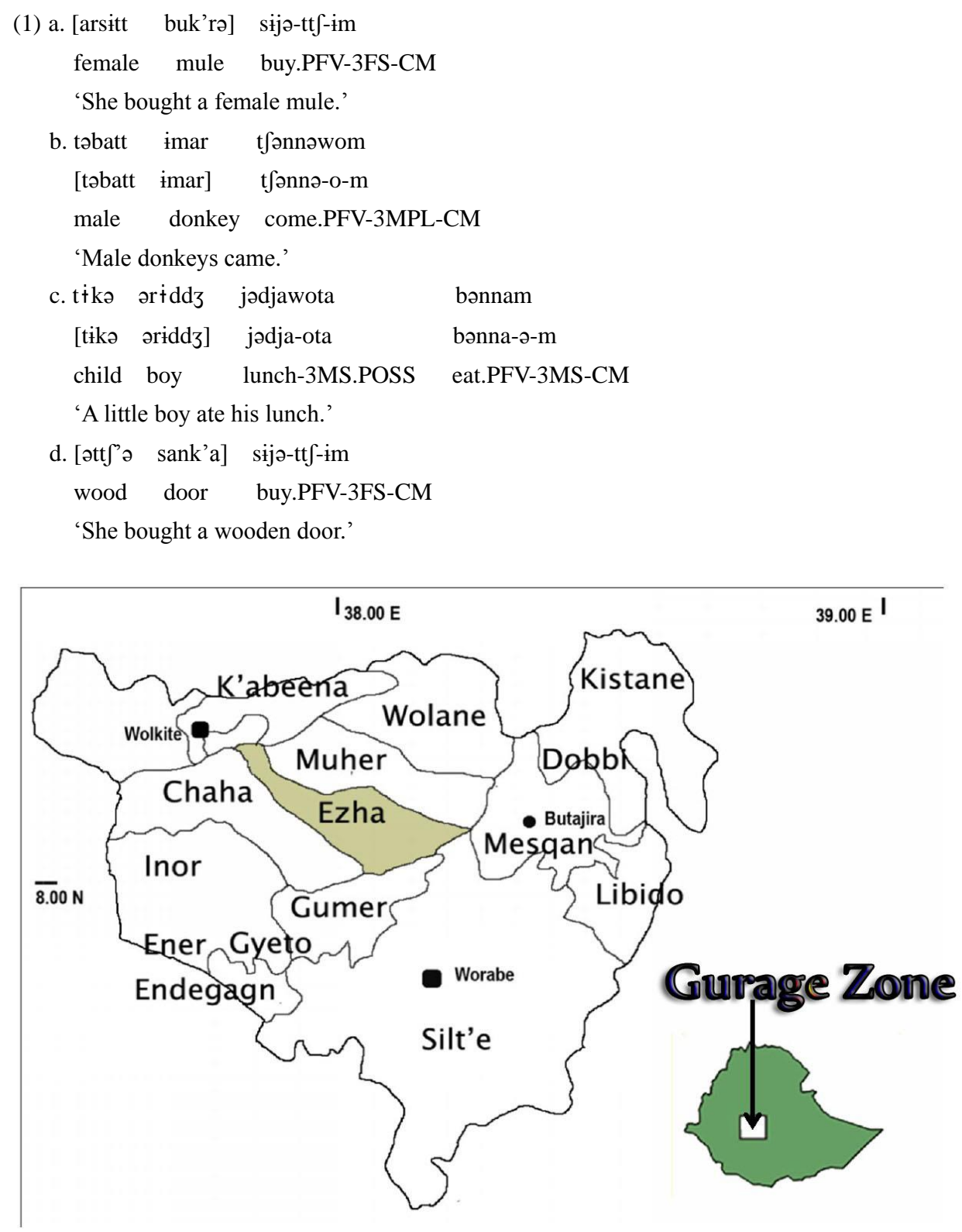

Figure 1. Geographical location of Ezha and surrounding languages 


\section{Endalew Assefa}

In the examples 1a-1c, the dependent constituents serve as modifiers of the head noun. The dependent constituent in 1d, on the other hand, is a complement to the head. This goes in line with Baye (2008) who stipulates that a dependent noun (phrase) accompanying the head of a matrix noun phrase serves as a complement if it denotes the material which the entity referred to by the head noun is made of. Following Baye, dependents like attf'a 'wood' in att S' sank'a 'a wooden door' are analyzed to be complements to their heads.

A head noun can also be accompanied by possessor nouns. In this case, the possessor noun attaches the genitive prefix $j{ }^{-}$, and precedes the possessed head noun as in the following examples.

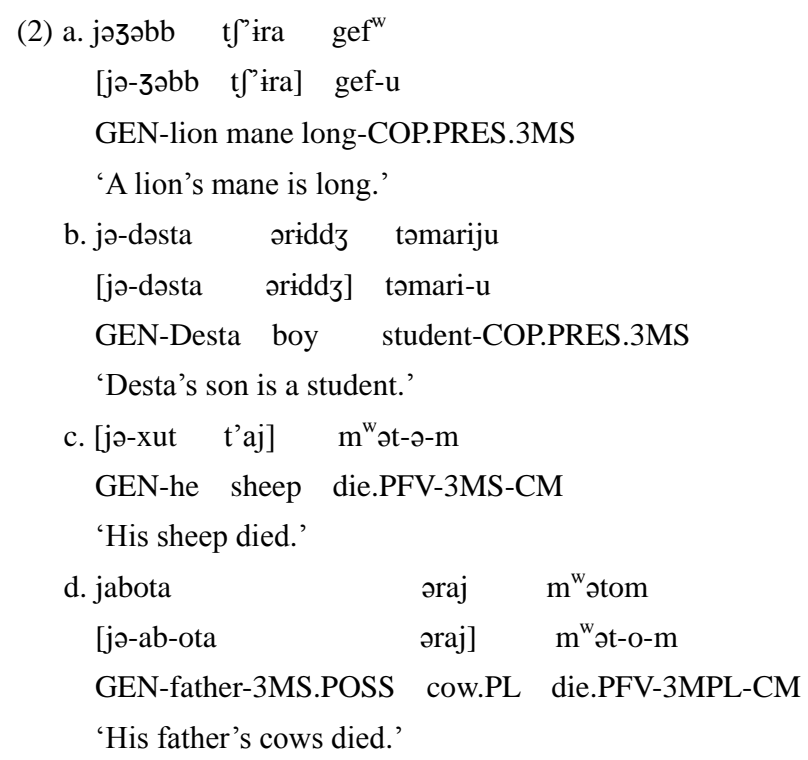

The examples depict that the genitive prefix can attach to both nouns and personal pronouns in order to express a possessor-possessed relationship between the dependent and the head constituents within a noun phrase. The head noun in $2 \mathrm{c}$ can have either a singular or plural reading since it is not specified for number, the distinction is made by considering the subject agreement suffixes attached to a verb in sentential constructions as in ex.3 below whereby the 3MS subject suffix - - and the 3MPL subject suffix $-o$ are attached to the verb indicating the singularity and plurality of the entities referred to by the head noun within the subject noun phrase.

In the example $2 \mathrm{~d}$, there exists the notion of double possession. The utterance ab-ota 'his father' on its own indicates possession in the sense that $a b$ 'father' is possessed by a third person singular masculine entity. When this noun phrase is marked by the genitive prefix and combined with the noun $r$ raj 'cows' to form the matrix phrase jabota araj 'my father's cows', another possessive reading is introduced; this notion of possession indicates that the 


\section{The Structure of a Noun Phrase in Ezha, Ethio-Semitic}

entities signaled by $ə r a j$ 'cows' are possessed by abota 'his father'.

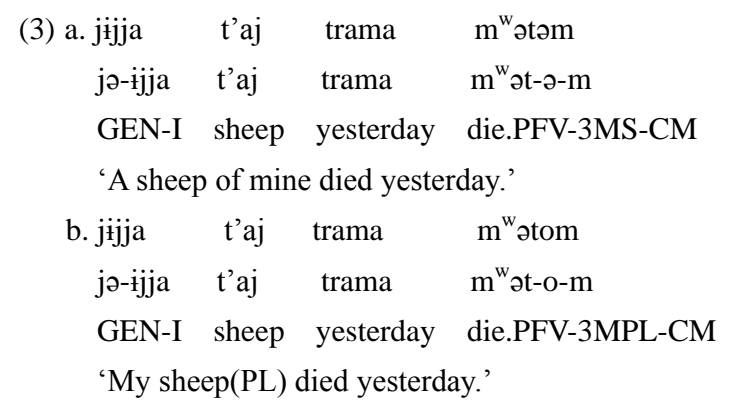

In some phrasal constructions, the genitive morpheme can attach to the dependent nouns without rendering any sense of possession as in the following examples.

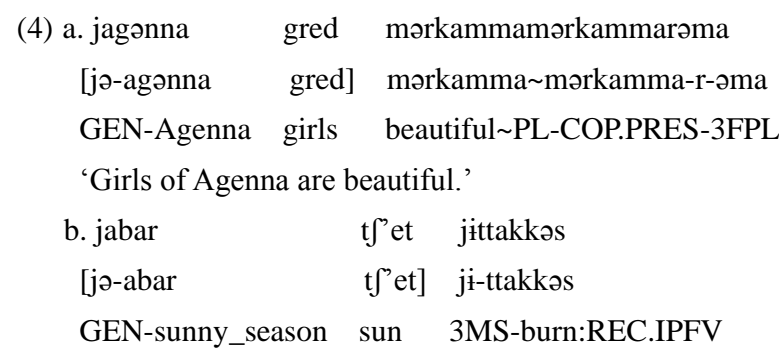

'The Sun of the summer season burns.'
c. [jə-məsk'ər kitf ${ }^{\mathrm{w}}$ ə] bənna- ${ }^{\mathrm{w}}$-m
GEN-Holy_Cross tatar eat.PFV-1S-CM
'I ate tatar of the Holy Cross holiday.'

The phrasal structures in ex.4 are formally analogous to those in ex.2 by virtue of having the genitive prefix attached to the dependent constituents. However, none of them expresses the notion of possession. In example $4 \mathrm{a}$, the dependent noun designates the origin of the entity denoted by the head noun. In the examples $4 \mathrm{~b} \& 4 \mathrm{c}$, on the other hand, the dependent constituents are meant to specify the entities referred to by the head nouns in terms of period of time or season when they are localized.

In situations where a definite head noun is preceded by dependent nouns, the definite morpheme attaches to the dependents and not to the head, neither does it to both at the same time as exemplified below.

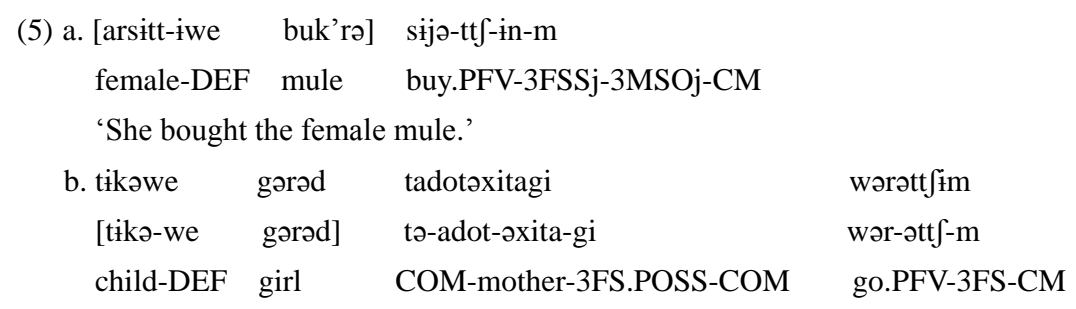




\section{Endalew Assefa}

'The little girl went with her mother.'

If a definite head noun is modified by a personal pronoun or a proper noun possessor, the definite morpheme need not have to occur. This adheres to the general rule that proper names and personal pronouns are inherently definite so that they do not need a definite marker, the definite reading of the head noun is signaled by the possessor pronouns and proper nouns themselves.

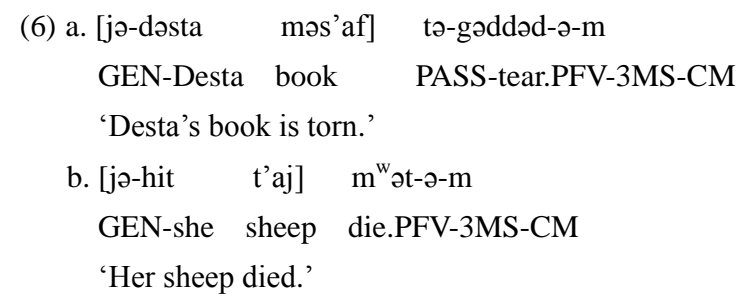

The head of a noun phrase can also select an adjective as its dependent. Such a dependent always precedes the head and serves as a modifier as demonstrated by the following examples.

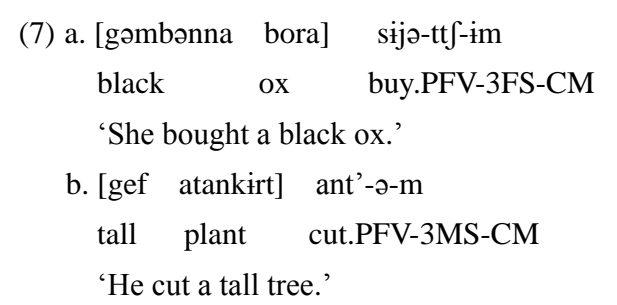

Ezha adjectives indicate plurality morphologically by complete reduplication. Hence, when the head of a noun phrase has a plural reading, the dependent adjective assumes its reduplicated form in order to agree with the number of the head noun.

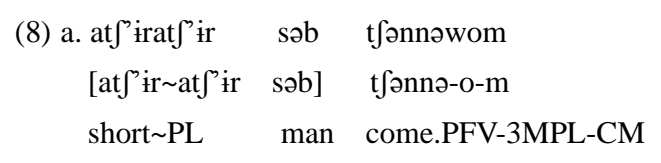

'Short men came.'

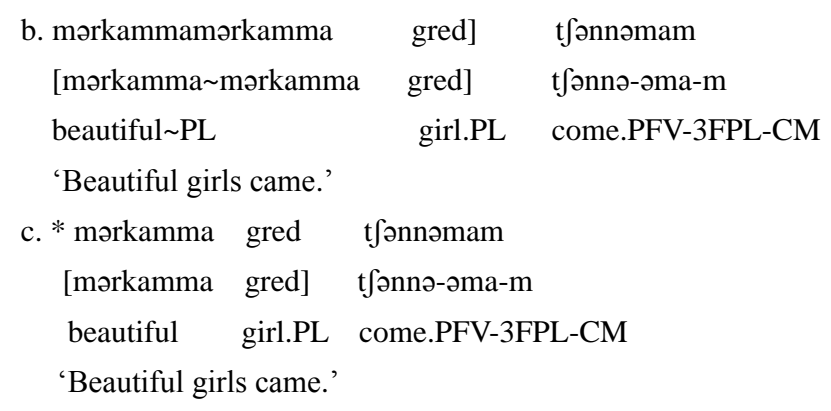

In example 8a, the head noun $s a b$ 'man' could have both singular and plural readings. As 


\section{The Structure of a Noun Phrase in Ezha, Ethio-Semitic}

such, when this noun is meant to render a singular reading, the preceding adjective must appear in its non-reduplicated form, whereas in situations where the head noun is meant to refer to plural entities, the adjective assumes its reduplicated form. The head of the phrasal construction in $8 \mathrm{~b}$, on the other hand, surfaces in its plural form; its singular counterpart is garad. Thus, it is only the reduplicated form of the adjective that can occupy the preceding slot within the noun phrase headed by this noun. The occurrence of the non-reduplicated adjective preceding the plural head noun results in an ill-formed construction as in 8c.

Two or more adjectives can also co-occur as modifiers of a head noun. In such a situation, the order of adjectives is not fixed; they can freely exchange positions with equal level of grammaticality.

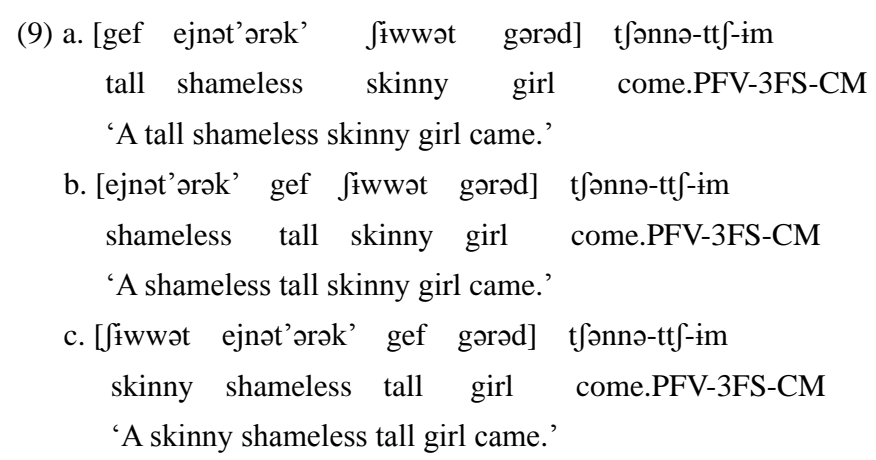

Adjectives attract the definite article when they occur in a definite noun phrase. When a series of adjectives co-occur within the same noun phrase headed by a definite noun, the definite marker attaches to the left-most modifying adjective.

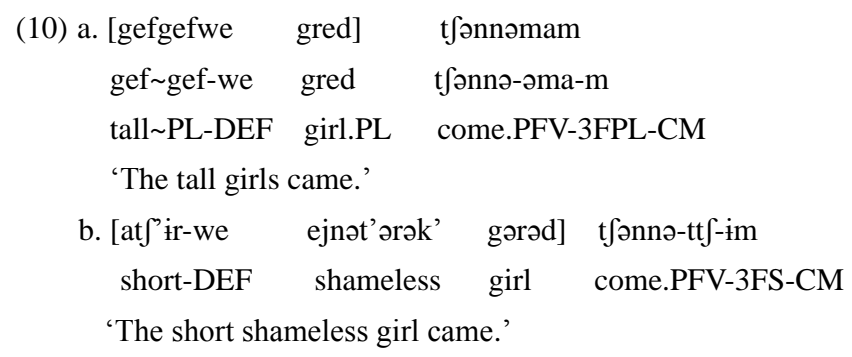

Like adjectives, numerals can modify a head noun. If a numeral precedes a definite head noun, the definite marker is suffixed to the numeral and not to the head noun as in ex.11.

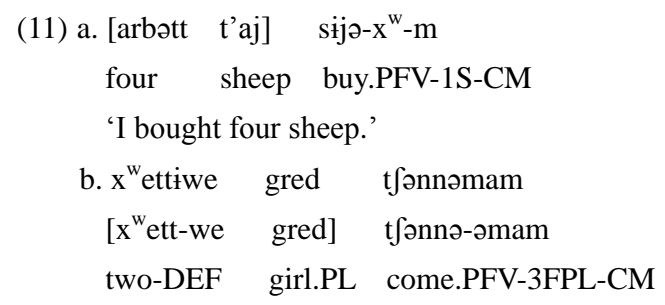




\section{Endalew Assefa}

'The two girls came.'

Numerals can also be combined with nouns to form measure phrases and classifier phrases, which in turn serve as modifiers of a head noun. Measure phrases in Ezha have nominal heads and signify units of measurement. They express precise amounts of entities designated by countable and mass nouns. Classifier phrases, on the other hand, do not use measurement or container terms. Though they are structurally analogous to measure phrases, classifier phrases are used to individualize an entity out of a universe category. The examples $12 \mathrm{a} \& 12 \mathrm{~b}$ below illustrate how measure phrases modify nouns, while examples $12 \mathrm{c} \& 12 \mathrm{~d}$ indicate noun phrases involving classifier phrases.

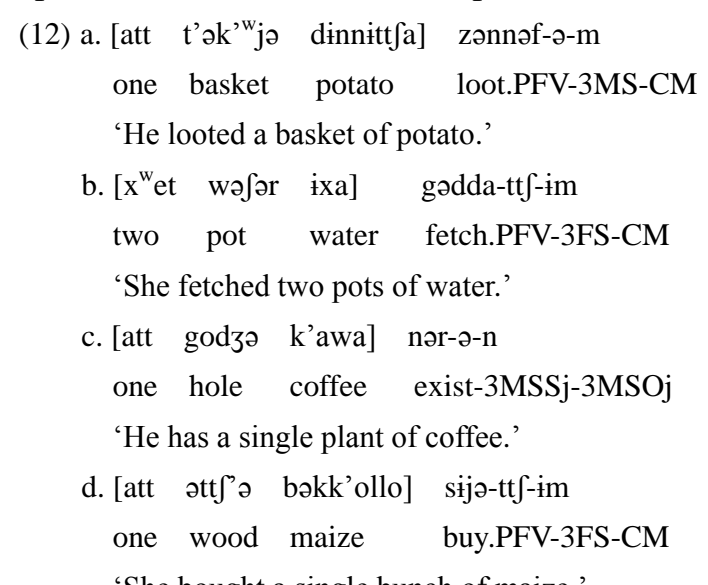

The other modifiers in a noun phrase are demonstratives. Both the proximal and distal demonstratives modify a head noun thereby specifying the object referred to by the head noun in terms of distance relative to the speaker and/or the hearer during a certain discourse. The demonstratives can precede singular and plural nouns as there is no number distinction on demonstratives; only very rarely speakers of the language introduce the associative plural morpheme $n \gtrsim$ - so as to express plurality.

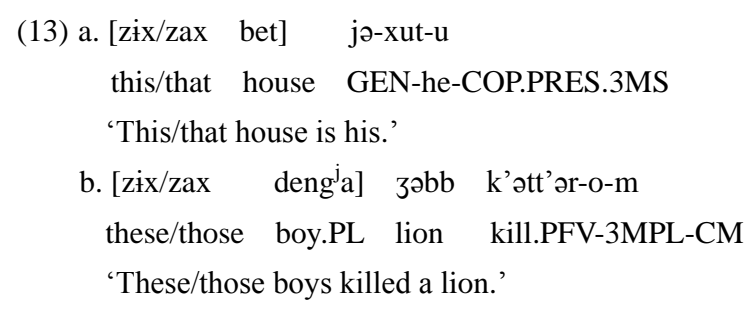

The definite marker -we never appears when demonstratives are used as modifiers of a definite head noun. The head noun along with the modifying demonstrative renders a definite reading without the occurrence of any definite marker. Thus, the nominal phrases indicated in ex.13 are specified for definiteness through the inherent definite nature of the 


\section{The Structure of a Noun Phrase in Ezha, Ethio-Semitic}

demonstratives.

A nominal head can also be modified by a relative clause which always precedes the head noun it modifies. Within the relative clause, the relative verb along with the relativizer prefix occurs as a final constituent of the clause.

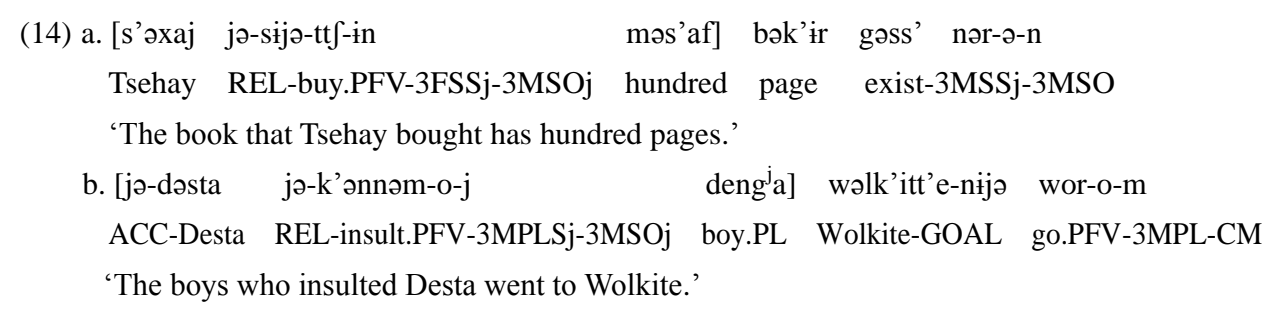

The relative verb shows concord with the relativized noun. Note that the $3 \mathrm{MSO}$ suffix surfaces as $-n$ in the example $14 \mathrm{a}$, whereas it occurs as $-j$ in the example $14 \mathrm{~b}$ due to the variation in the subject.

The different dependents addressed so far can co-occur with a single head noun. In such a case, the basic constituent order is Demonstrative-Relative clause- Numeral- Adjective(possessor) Noun-Head Noun. There is, however, a considerable degree of flexibility for the dependents to exchange their positions. For instance, the numeral can follow the adjective, and the possessor noun can precede the numeral and the adjective. The relative clause can be situated everywhere except that it cannot follow the possessor noun modifier. If there is a noun serving as a complement of the head noun, it always occurs immediately before the head. The demonstrative either follows the relative clause within the basic constituent sequence or assumes the initial position of the phrase. The following data present some possible co-occurrences of the different dependent constituents preceding a head noun.

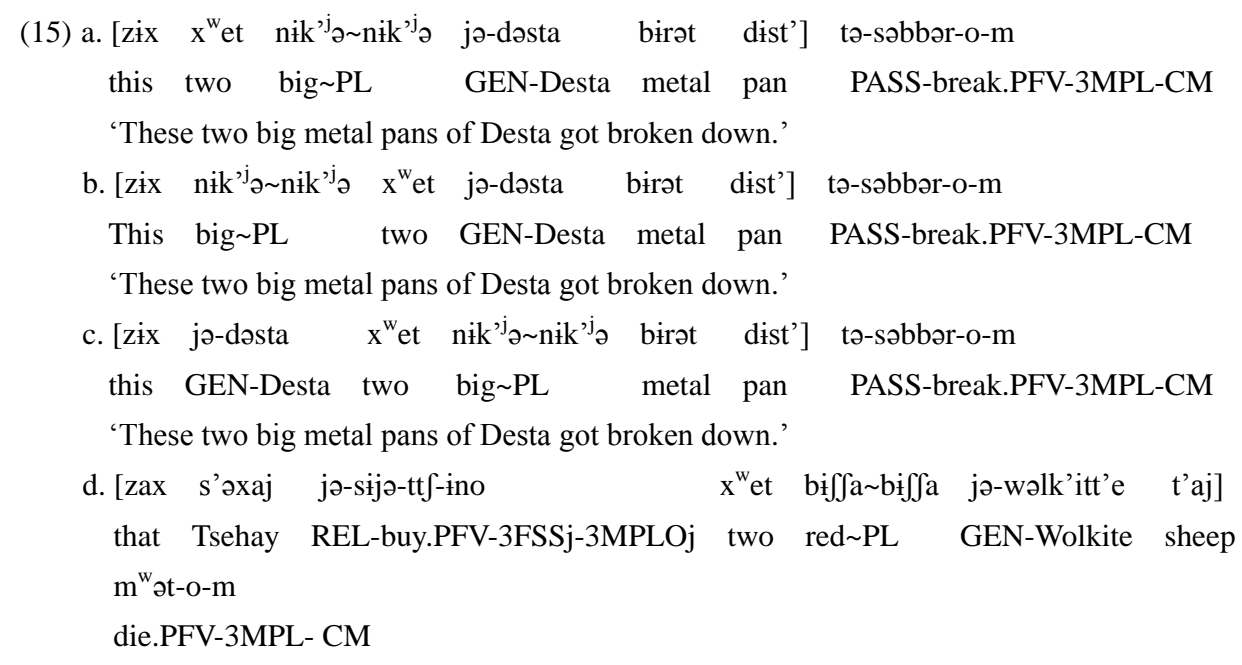




\section{Endalew Assefa}

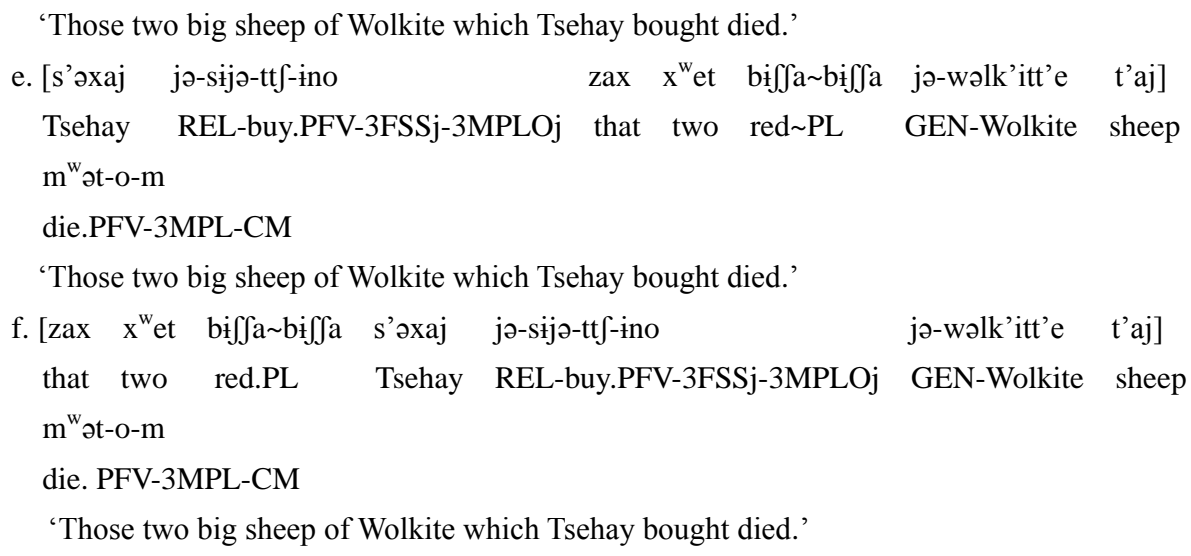

\section{Conclusion}

A noun phrase in Ezha can be constructed out of a head noun alone or the head together with dependents. If dependents occur within a noun phrase, they could be nouns, adjectives, numerals, demonstratives and/or relative clauses. All dependents modify the head noun restrictively, they are meant to restrict the potential reference of the modified noun in some way. For example, in the phrases gəmbənna zəbb 'a black lion' and zix t'aj 'this/these sheep', the adjective gəmbanna 'black' and the demonstrative zix 'this/these' restrictively modify the nouns $z a b b$ 'lion' and $t$ ' $a j$ 'sheep' respectively.

If the head nouns were to occur alone, they could potentially refer to any types of entities. The modifiers restrict the references of the phrases to just a lion that is black and a/those sheep that is/are currently addressed by the speaker. In situations where multiple modifiers co-occur with a head noun, each of them poses its effect in restricting the potential reference of the modified noun. The result of piling up modifiers is that the actual referent of the phrase must satisfy all of them for each modifier acts as a criterion that the ultimate referent(s) of the phrase must satisfy.

It is also worth noting that none of the modifiers are required or implied by the head nouns they modify. The phrases would be grammatically complete without the modifiers though adding or removing modifiers affects the potential referential scope of the modified elements, hence, the possibility of having a noun phrase constructed out of a head noun alone.

\section{Symbols and abbreviations}

$\begin{array}{ll}\text { 1, 2, } 3 & \text { First, second and third person } \\ \text { CM } & \text { Clause Marker } \\ \text { COM } & \text { Comitative }\end{array}$




\section{The Structure of a Noun Phrase in Ezha, Ethio-Semitic}

$\begin{array}{ll}\text { COP } & \text { Copula } \\ \text { DEF } & \text { Definite } \\ \text { F } & \text { Feminine } \\ \text { GEN } & \text { Genitive } \\ \text { M } & \text { Masculine } \\ \text { Oj } & \text { Object } \\ \text { PASS } & \text { Passive } \\ \text { PFV } & \text { Perfective } \\ \text { PL } & \text { Plural } \\ \text { POSS } & \text { Possessive } \\ \text { PRES } & \text { Present } \\ \text { REC } & \text { Reciprocal } \\ \text { REL } & \text { Relativiser } \\ \text { S } & \text { Singular } \\ \text { Sj } & \text { Subject }\end{array}$

\section{References}

Abza, T. 2001. Noun morphology of Ezha [D]. Senior Essay. Department of Linguistics, Addis Ababa University.

- 2008. Comparative Morphology of Ezha, Kistane and Muher [D]. MA Thesis. Department of Linguistics, Addis Ababa University.

Assefa, E. 2010. The Syntax of Ezha Nominal Functors [M]. USA: VDM Publishing House Limited.

. 2014. Descriptive Grammar of Ezha: A Central West Gurage Language, Ethio-Semitic [D]. PhD

Dissertation. Department of Linguistics, Addis Ababa University.

Bauer, L. 2003. Introducing Linguistic Morphology [M]. Edinburgh University Press.

Halliday, M. 1994. An Introduction to Functional Grammar [M]. London: Arnold.

Hetzron, R. 1972. Ethiopian Semitic. Studies in Classification [M]. Manchester: Manchester University press.

_. 1977. The Gunnän Gurage Languages [M]. Naples: Instituto Oriental di Napoli.

1996. The Two Futures in Central and Peripheral Western Gurage [A]. In Grover Hudson (ed.)

Essays on Gurage languages and culture [C]. Wiesbaden: Harrassowitz. 153- 173.

Hetzron, R. and Bender, M. 1976. The Ethio-Semitic Languages [A]. In Bender, M. et al (eds.) Language in Ethiopia [C]. London: Oxford University press. 23-33.

Katamba, F. 1993. Morphology [M]. London, Michigan: Penguin Books Limited.

Leslau, W. 1950. Ethiopic Documents: Gurage [M]. New York: Viking Fund.

- 1967. The Jussive in Ezha [J]. Journal of Semitic studies (Manchester), 12(1): 65-82.

_ 1969a. Towards the Classification of Gurage Dialects [J]. Journal of Semitic Studies, 14:96-109.

1969b. Ezha Riddles [J]. Rassegna di Studi Ethiopic, 23:43-78.

1979a. Etymological Dictionary of Gurage (Ethiopic). Volume-I: Individual Dictionaries [M]. Wiesbaden: Harrassowitz.

1979b. Etymological Dictionary of Gurage (Ethiopic). Volume-II: English-Gurage Index [M]. Wiesbaden: Harrassowitz.

1979c. Etymological Dictionary of Gurage (Ethiopic). Volume-III: Etymological Section [M]. Wiesbaden: Harrassowitz.

Matthews, P. H. 1991. Morphology [M]. Cambridge: Cambridge University Press.

Menuta, F. 2002. Morphology of Ezha [D]. MA Thesis. Department of Linguistics, Addis Ababa University.

Meyer, R. 2006. Wolane, Descriptive Grammar of an East Gurage Language (Ethiosemitic) [M]. Köln: Köppe.

. 2011. Gurage [A]. In Weninger, S. et al (eds.). The Semitic Languages: An International Handbook 


\section{Endalew Assefa}

[C]. De Gruyter Mouton. 1220-1275.

Payne, T. 1997. Describing Morphosyntax: A Guide for Field Linguistics [M]. Cambridge: Cambridge University Press.

Petros, D. 2000. Sound Mutation: The Morphology of Chaha [M]. Philadelphia and Amsterdam: Benjamins.

Polotsky, H. J. 1951. Notes on Gurage Grammar [M]. Jerusalem: Israel Central Press.

Rose, S. 2007. Chaha (Gurage) [A]. In Kaye, A. (ed.) Morphologies of Asia and Africa [C] Vol. 1. Winona Lake, Indianna: Eisenbrauns. 403-427.

Tsegaye, A. 2012. Deixis in Ezha [D]. MA Thesis. Department of Linguistics, Addis Ababa University.

Yimam, B. 2008. jamarinna sawasiw (Amharic Grammar) [M]. Addis Ababa: Eleni Private Limited Press. 